\title{
Short-Term Effects of Heat on Mortality and Effect Modification by Air Pollution in 25 Italian Cities
}

\author{
Matteo Scortichini ${ }^{1}$, Manuela De Sario ${ }^{1}{ }^{(D)}$, Francesca K. de'Donato ${ }^{1}$, Marina Davoli ${ }^{1}$, \\ Paola Michelozzi ${ }^{1}$ and Massimo Stafoggia ${ }^{1,2, *}$ \\ 1 Department of Epidemiology, Lazio Regional Health Service, ASL Roma 1, 00147 Rome, Italy; \\ m.scortichini@deplazio.it (M.S.); m.desario@deplazio.it (M.D.S.); f.dedonato@deplazio.it (F.K.d.D.); \\ m.davoli@deplazio.it (M.D.); p.michelozzi@deplazio.it (P.M.) \\ 2 Institute of Environmental medicine, Karolinska Institutet, Box 210, SE-171 77 Stockholm, Sweden \\ * Correspondence: m.stafoggia@deplazio.it; Tel.: +39-06-99722185
}

Received: 1 July 2018; Accepted: 14 August 2018; Published: 17 August 2018

\begin{abstract}
Evidence on the health effects of extreme temperatures and air pollution is copious. However few studies focused on their interaction. The aim of this study is to evaluate daily PM10 and ozone as potential effect modifiers of the relationship between temperature and natural mortality in 25 Italian cities. Time-series analysis was run for each city. To evaluate interaction, a tensor product between mean air temperature (lag 0-3) and either PM10 or ozone (both lag 0-5) was defined and temperature estimates were extrapolated at low, medium, and high levels of pollutants. Heat effects were estimated as percent change in mortality for increases in temperature between 75th and 99th percentiles. Results were pooled by geographical area. Differential temperature-mortality risks by air pollutants were found. For PM10, estimates ranged from 3.9\% (low PM10) to $14.1 \%$ (high PM10) in the North, from 3.6\% to $24.4 \%$ in the Center, and from $7.5 \%$ to $21.6 \%$ in the South. Temperature-related mortality was similarly modified by ozone in northern and central Italy, while no effect modification was observed in the South. This study underlines the synergistic effects of heat and air pollution on mortality. Considering the predicted increase in heat waves and stagnation events in the Mediterranean countries such as Italy, it is time to enclose air pollution within public health heat prevention plans.
\end{abstract}

Keywords: air pollution; heat; air temperature; mortality; effect modification

\section{Introduction}

Numerous epidemiological studies have reported the acute effects of air pollutants on mortality for non-accidental and cardiopulmonary causes [1,2]. Similarly, there is literature showing a significant and immediate ( $0-3$ days) association between heat and daily mortality, with non-linear effects of high summer temperatures or linear above a threshold [3,4]. Results are consistent across different geographical areas, although some heterogeneity exists depending on local population characteristics and climatic conditions $[2,4,5]$. Furthermore, the same vulnerable population subgroups, such as the elderly and patients with cardio-respiratory disease and diabetes, have been identified in relation to short-term effects of heat or air pollution [6-10].

It is common practice in epidemiological time series studies to adjust for daily temperature when investigating the relationship between air pollution [11] and, to a lesser extent, control for daily air pollution levels in the analysis of extreme temperatures effects [12].

In contrast, the interactive or synergistic effects of the two environmental exposures on mortality has been less investigated. In the last decade, several studies focused on this aspect, mostly by providing effects of air pollutants stratified by season $[13,14]$ and showing the highest effects in 
summer, especially of $\mathrm{PM}$ and $\mathrm{O}_{3}$ [15-17]. They all agree that the two exposures, air temperature and air pollution (either $\mathrm{PM}$ or $\mathrm{O}_{3}$ ), display a synergistic effect on mortality, with joint exposures increasing daily mortality risk more than the sum of the two individual effects. However, the shape and mechanisms of such interactions remain unclear [18].

While temperature has been shown to modify the air pollution-mortality relationship [16,17], much less is known on the potential effect modification induced by daily air pollutants on the association between air temperature and mortality in the warm season [19]. To our knowledge, this has never been investigated in Italy and only marginally elsewhere [19-22].

Recently, the fifth Assessment Report of the Intergovernmental Panel on Climate Change (IPCC) has identified the Mediterranean area as one of the most vulnerable hot spots to climate change for the 21st century [23]. Italy is particularly at risk due to the dominant high pressure during summer, which is associated with heat waves and the build-up of pollutants that entail the exceedance air quality standards especially in larger urban areas [24]. The objective of the study is to investigate the joint relationship between heat and air pollutants concentrations (PM and ozone) on daily mortality in 25 major Italian cities during summer. To address this aim, only deaths occurring in the warm season (defined as April to September) were selected. We estimated city-specific joint exposure-response curves of the two environmental risk factors (temperature and PM or ozone in turn) on daily non-accidental mortality, and we pooled the results into a meta-analysis where the association between summer temperature and mortality by low, medium, and high levels of the two air pollutants was reported. This aspect is of particular relevance in terms of public health prevention measures in urban areas during summer as heat waves and high levels of pollution are likely to occur concurrently, and adequate measures should be implemented to tackle both issues with particular focus on subgroups at risk.

\section{Materials and Methods}

\subsection{Dataset}

Data was collected for 25 Italian cities (Ancona, Bari, Bologna, Brindisi, Cagliari, Ferrara, Firenze, Genova, Mestre-Venezia, Milano, Modena, Napoli, Padova, Palermo, Parma, Piacenza, Pisa, Reggio Emilia, Rimini, Roma, Rovigo, Taranto, Torino, Treviso, and Trieste) included in the national project EPIAIR2 [1]. Figure S1 shows the geographical distribution of the 25 cities included in the study: the different colors represent the three areas-North, Center, and South. All cities are larger than 80,000 inhabitants (except Rovigo, with circa 50,000 residents). For each city daily mortality, meteorological and air pollution data for the period 2006-2010 was provided depending on availability.

Briefly, the outcome variable considered in this study was the city-specific daily mortality count for non-accidental causes (International Classification of Diseases 9th or 10th version [ICD-9] 001-799 or [ICD-10] A00-R99) among subjects of age 35+ years residing and dying in each of the 25 cities.

Temperature data was retrieved from the airport station closest to each city. Daily mean temperature $\left({ }^{\circ} \mathrm{C}\right)$ was calculated as the average of the 6 - $\mathrm{h}$ temperature readings in the $24 \mathrm{~h}$ period.

The air pollutants considered in the analysis were PM10 and $\mathrm{O}_{3}$. The regional air quality monitoring networks provided, for each city, the daily time series of pollutants, retrieved from urban monitors. Only monitors meeting the requirements of EPIAIR2 protocol were included in the analysis [25]. The same protocol was applied to impute missing values for each monitor and to derive daily mean concentrations for PM10, and daily maximum 8-h running means for $\mathrm{O}_{3}$. 


\subsection{Statistical Methods}

We ran an over-dispersed Poisson generalized additive regression model in each city, as the following:

$\log \left[\mathrm{E}\left(\mathrm{Y} \_\mathrm{i}\right)\right]=\alpha+$ tensor $\left(\llbracket T\right.$ mean $\rrbracket\left((0-3)\right.$, [Pollutant $\left.\rrbracket \_(0-5)\right)+\mathrm{s}($ time $)+\mathrm{s}(\mathrm{dos})+\mathrm{dow}+\mathrm{hol}+$ pop_hol

where $Y \_i$ is the number of non-accidental deaths in the day $i$; Tmean0-3 is a moving average of the daily mean temperature of the current day and previous three days; Pollutant $0-5$ is a moving average of the daily concentration of air pollutant considered in the model (either PM10 or $\mathrm{O}_{3}$ ) of the current day and previous five days; Time is the progressive count of days in the study period, modelled with a spline with a number of degrees of freedom (d.o.f.) equal to the city specific number of years available; dos is the day of season (values from 1 to 183) fitted with a spline with six d.o.f. (one for each month) to control for sub-seasonal trends; dow and hol are categorical variables for day of the week and holidays, respectively; and pop_hol is a categorical variable accounting for population decrease during the summer vacation periods (it assumes value " 2 " in the two-week period around mid-August, value " 1 " between mid-July and 31st of August (with the exception of the aforementioned two-week period), and value " 0 " otherwise). The lag windows for air temperature and air pollutants were defined a priori, based either on literature [26] or on previous investigations on the same dataset [1].

The interaction between temperature and air pollution was analyzed by running a "response surface" model: this methodology allows us to represent the combined relationship between two risk factors and the outcome of interest with a non-parametric approach by defining a tensor smoother, i.e., a tridimensional curve modeling the increases in mortality according to a combined variation of the values of temperature and air pollutant. The tensor was estimated by fitting a cubic spline with four d.o.f. for temperature and a cubic spline with three d.o.f. for pollutants.

A random-effects meta-analysis was run to obtain pooled estimates at country level and by geographic areas, defined as North (Treviso, Trieste, Milano, Venezia, Padova, Rovigo, Torino, Piacenza, Ferrara, Parma, Reggio Emilia, Modena, Bologna, Genova, Rimini), Center (Firenze, Pisa, Ancona, Roma), and South (Bari, Napoli, Brindisi, Taranto, Cagliari, Palermo). The effect of heat was estimated as the \% change in mortality, with $95 \%$ confidence intervals $(95 \% \mathrm{CI})$, for an increase in mean temperature from the 75th to the 99th percentile of the city-specific distribution of mean temperature.

In order to evaluate if the effect of temperature was modified by air pollution, three levels of air pollution considered as "low," "medium," and "high" were defined for each city, equals to the 5th, 50th and 95th percentile of the city-specific air pollutants distributions. Then, from the tridimensional surface estimated in each city, three dose-response curves were extrapolated along the aforementioned values of pollutants, expressing the relationship between temperature and mortality corresponding to low, medium, and high pollution values. Finally, the \% change in mortality was estimated from each curve, and $95 \%$ confidence intervals were calculated with a bootstrap procedure.

A graphical example of the tensor smoother, with temperature effects stratified by pollutants values, is displayed in Figure 1. The graph shows the percentiles chosen to express effect estimates of temperature (75th and 99th percentiles of temperature distribution) and the sections corresponding to low, medium and high pollution values (5th, 50th, and 95th percentiles of PM10 distribution).

To test for the presence of effect modification by air pollution, the Cochran $\mathrm{Q}$ test and $\mathrm{I}^{2}$ statistic were estimated on the effects pooled by geographic area.

All analyses were conducted using the packages $\mathrm{mgcv}$, metafor.in R statistical software [27]. 


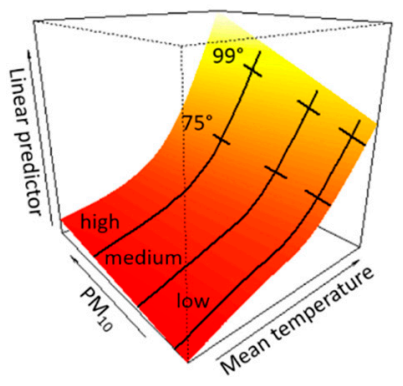

Figure 1. Example of the tensor smoother depicting the joint non-linear association between mean temperature and PM10 on non-accidental mortality. The graph shows the percentiles chosen to show effect estimates of temperature (75th and 99th percentiles of temperature distribution) and the sections corresponding to low, medium and high pollution values (5th, 50th, and 95th percentiles of PM10 distribution).

\section{Results}

Study cities average population varies from 52,118 residents in Rovigo to 2,743,796 in Roma (Table S1). Considering the three geographic areas, total population is around 5 million in the North, 3.3 million in the Center and 2.4 million in the South. There is a clear South-North gradient in the proportion of elderly residents (65+), ranging from $18.4 \%$ to $24.5 \%$. The geographical gradient is steeper among the very old (85+).

Table 1 shows, for each city, the study period, total and daily deaths in the 35+ years population, mean and standard deviation of air temperature distributions, and the percentiles used to estimate the effect of heat (75th and 99th percentiles) and the concentrations of pollutants used to define low, medium, and high levels of PM10 and $\mathrm{O}_{3}$ by city. According to this study, 187,743 subjects aged $35+$ years died from non-accidental causes in the study period in the 25 cities, with a high heterogeneity in the daily number of deaths (from 1.3 in Rovigo to 54.0 in Roma). A high variability was also observed for mean temperature $\left(19.7^{\circ} \mathrm{C}\right.$ in Torino, $23.1^{\circ} \mathrm{C}$ in Palermo), with an increasing North to South gradient also observed in the 75th and 99th percentiles of the city-specific temperature distributions. For air pollutants, no major geographical patterns were detected, with highest PM10 values in the Po Valley area (Milano, Venezia, Padova, Torino) but also in central and southern major cities (Firenze, Roma, Napoli, Bari, and Palermo).

City-specific heat effects are shown in Figure 2. A significant effect of heat on mortality is observed in most cities for temperature increases between the 75th and 99th percentile of the mean temperature distributions. Furthermore, no clear geographical trend is observed, with the highest effects of heat in Bologna, Bari, and Ancona, respectively, from the North, South, and central regions. The overall meta-analytical effect is significant (results not shown), with similar magnitudes in southern (\% change +15.2 ; 95\% CI: $8.4-22.3$ for temperature increases from 75th to 99th percentile) and central cities (\% change $+15.1 ; 95 \%$ CI: 8.8-21.8) and slightly lower effects observed in northern cities (\% change $+10.1 ; 95 \%$ CI: 7.2-13.2). 
Table 1. Description of city-specific data: study period, mortality data in 35+ years population, air temperature distribution and percentiles of air pollutants used to define days with low, medium, and high PM10 and $\mathrm{O}_{3}$ values.

\begin{tabular}{|c|c|c|c|c|c|c|c|c|c|c|c|c|c|c|}
\hline \multirow{2}{*}{ Area } & \multirow{2}{*}{ City } & \multirow{2}{*}{ Study Period } & \multicolumn{2}{|c|}{ Mortality for Natural Causes } & \multicolumn{4}{|c|}{ Mean Temperature } & \multicolumn{3}{|c|}{$\mathrm{PM}_{10}$} & \multicolumn{3}{|c|}{$\mathrm{O}_{3}$} \\
\hline & & & $n$. & Daily Mean & Mean & SD & $75^{\circ}$ pctile & $99^{\circ}$ pctile & $5^{\circ}$ pctile & $50^{\circ}$ pctile & $95^{\circ}$ pctile & $5^{\circ}$ pctile & $50^{\circ}$ pctile & $95^{\circ}$ pctile \\
\hline \multirow{16}{*}{ North } & Treviso & $2006-2010$ & 3202 & 2.2 & 13.8 & 7.9 & 23.8 & 29.1 & 5.0 & 24.0 & 45.7 & 55.6 & 103.8 & 158.9 \\
\hline & Trieste & 2006-2010 & 12,818 & 7.0 & 15.7 & 7.0 & 24.6 & 28.9 & 7.5 & 20.0 & 39.6 & 64.8 & 97.3 & 136.8 \\
\hline & Milano & $2006-2010$ & 51,710 & 28.3 & 13.9 & 8.3 & 24.7 & 29.0 & 12.0 & 28.6 & 51.5 & 45.7 & 92.1 & 150.4 \\
\hline & Venezia & $2006-2009$ & 6827 & 4.7 & 14.3 & 8.0 & 24.5 & 29.0 & 11.1 & 30.0 & 59.0 & 56.4 & 92.7 & 138.2 \\
\hline & Padova & 2006-2009 & 8640 & 5.9 & 13.7 & 8.2 & 24.1 & 28.6 & 10.0 & 31.5 & 58.1 & 57.4 & 106.8 & 162.6 \\
\hline & Rovigo & 2006-2010 & 2050 & 1.4 & 13.7 & 8.0 & 23.8 & 27.6 & 11.0 & 24.0 & 46.0 & 70.3 & 112.6 & 161.0 \\
\hline & Torino & 2006-2010 & 37,104 & 20.4 & 12.9 & 8.3 & 23.3 & 27.7 & 10.5 & 27.5 & 53.9 & 60.3 & 105.4 & 161.1 \\
\hline & Piacenza & $2006-2010$ & 5019 & 2.7 & 14.4 & 8.5 & 25.3 & 29.2 & 10.5 & 25.0 & 46.4 & 51.3 & 102.7 & 158.3 \\
\hline & Ferrara & 2006-2010 & 7875 & 4.3 & 14.6 & 8.3 & 25.2 & 29.6 & 11.0 & 24.0 & 43.0 & 71.1 & 109.3 & 153.0 \\
\hline & Parma & 2006-2010 & 8545 & 4.7 & 15.2 & 8.4 & 26.0 & 30.4 & 10.7 & 24.0 & 45.6 & 56.9 & 105.0 & 150.3 \\
\hline & Reggio Emilia & 2006-2010 & 6519 & 3.6 & 14.8 & 8.4 & 25.7 & 30.2 & 11.7 & 25.0 & 46.1 & 61.1 & 107.6 & 162.3 \\
\hline & Modena & $2006-2010$ & 8599 & 4.7 & 14.6 & 8.4 & 25.5 & 30.0 & 12.7 & 26.3 & 48.8 & 56.4 & 106.1 & 158.7 \\
\hline & Bologna & $2006-2010$ & 19,223 & 10.5 & 14.7 & 8.6 & 25.9 & 30.6 & 14.0 & 26.0 & 47.0 & 44.9 & 91.8 & 148.0 \\
\hline & Genova & 2006-2010 & 14,623 & 20.0 & 15.8 & 6.6 & 24.0 & 28.2 & 14.2 & 25.2 & 41.6 & 64.7 & 99.5 & 134.4 \\
\hline & Rimini & 2006-2010 & 5724 & 3.1 & 15.1 & 7.6 & 24.6 & 29.3 & 12.5 & 25.2 & 43.2 & 59.1 & 92.9 & 132.1 \\
\hline & Firenze & $2006-2010$ & 15,082 & 10.3 & 15.5 & 7.2 & 24.9 & 28.8 & 17.4 & 30.1 & 49.2 & 66.1 & 104.2 & 143.3 \\
\hline \multirow{3}{*}{ Center } & Pisa & $2006-2010$ & 3513 & 2.4 & 15.0 & 6.7 & 23.5 & 27.3 & 15.6 & 28.2 & 44.0 & 65.9 & 95.2 & 126.5 \\
\hline & Ancona & $2006-2010$ & 4447 & 2.4 & 14.8 & 7.1 & 23.9 & 28.8 & 15.2 & 28.9 & 51.3 & 43.2 & 85.7 & 115.5 \\
\hline & Roma & 2006-2010 & 104,795 & 57.4 & 15.9 & 7.0 & 25.4 & 29.4 & 17.3 & 30.3 & 50.0 & 62.7 & 95.1 & 134.2 \\
\hline \multirow{6}{*}{ South } & Bari & $2006-2010$ & 4812 & 6.6 & 16.1 & 6.8 & 25.0 & 30.8 & 14.8 & 28.4 & 52.0 & 64.4 & 98.4 & 126.1 \\
\hline & Napoli & $2006-2009$ & 33,443 & 22.9 & 16.9 & 6.5 & 25.7 & 29.0 & 12.4 & 30.6 & 59.2 & 45.6 & 100.6 & 141.0 \\
\hline & Brindisi & 2006-2010 & 2404 & 1.6 & 17.6 & 6.5 & 26.5 & 30.1 & 7.1 & 22.5 & 44.5 & 78.1 & 105.3 & 133.1 \\
\hline & Taranto & $2006-2010$ & 5881 & 4.0 & 17.5 & 6.7 & 26.8 & 30.8 & 13.3 & 26.4 & 52.9 & 80.1 & 110.7 & 145.5 \\
\hline & Cagliari & 2006-2010 & 6355 & 3.5 & 17.4 & 6.0 & 25.5 & 29.0 & 13.1 & 24.3 & 44.2 & 47.1 & 69.7 & 92.4 \\
\hline & Palermo & 2006-2009 & 22,116 & 15.1 & 18.8 & 6.0 & 26.7 & 31.0 & 19.8 & 32.9 & 63.9 & 56.1 & 79.8 & 102.1 \\
\hline
\end{tabular}


- North - Center - South

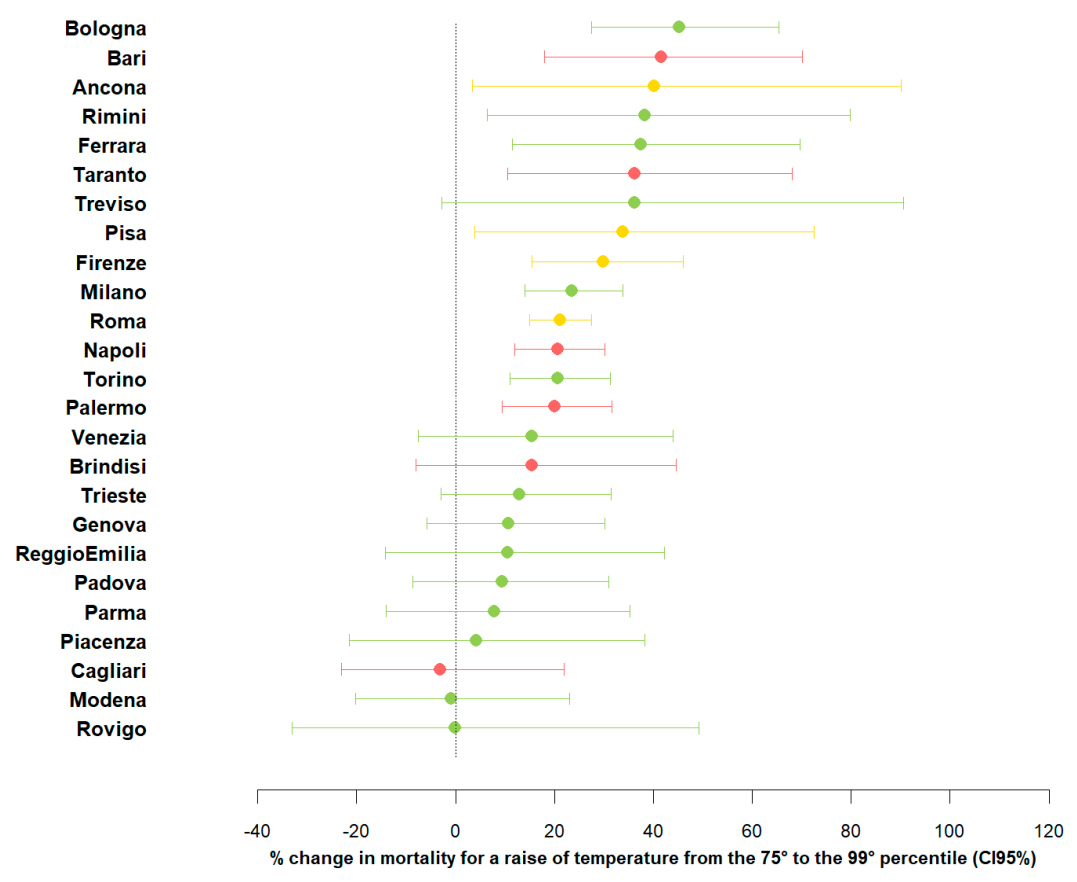

Figure 2. City-specific estimates of the heat effects. Estimates are given as \% change in non-accidental mortality, and $95 \%$ confidence intervals (95\% CI) for mean air temperature increases between the 75 th and 99th percentile of city-specific temperature distributions.

Figures 3 and 4 show area-specific (North, Center, South) and overall meta-analytical estimates of the effect of heat, stratified by levels of $\mathrm{PM} 10$ and $\mathrm{O}_{3}$ respectively (city-specific estimates are reported in supplementary material, Tables S2 and S3). In the North, a raise in mean temperature (from 75th to 99th percentile) caused an increase in mortality of $+3.9 \%\left(95 \% \mathrm{CI}:-2.1-10.2 ; \mathrm{I}^{2}=43 \%\right)$ on days with low levels of PM10, while on days characterized by medium or high concentrations, the increases were equal to $+10.8 \%\left(95 \%\right.$ CI: $\left.6.1-15.6 ; \mathrm{I}^{2}=58 \%\right)$ and $+14.1 \%\left(95 \%\right.$ CI: $\left.10.0-18.3 \mathrm{I}^{2}=0 \%\right)$, respectively. In the Center, the trend was even steeper: the increases in temperature-related mortality rose from $+3.6 \%\left(95 \%\right.$ CI: $\left.-1.3-8.8 \mathrm{I}^{2}=0 \%\right)$ to $+14.9 \%\left(95 \%\right.$ CI: $\left.10.7-19.3 \mathrm{I}^{2}=10 \%\right)$ and $+24.4 \%(95 \%$ CI: $17.6-31.6$ $\mathrm{I}^{2}=15 \%$ ) for days with low, medium, and high PM10 concentrations, respectively. A similar trend was found in southern cities, with estimates ranging between $+7.5 \%\left(95 \% \mathrm{CI}:-1.6-17.3 \mathrm{I}^{2}=25 \%\right)$ to $+15.5 \%\left(95 \%\right.$ CI: $\left.6.8-24.9 \mathrm{I}^{2}=54 \%\right)$ and $+21.6 \%\left(95 \%\right.$ CI: $\left.4.2-41.9 \mathrm{I}^{2}=82 \%\right)$. The overall estimates on all the 25 cities confirms the increasing trend observed in the area-specific results.

Corresponding results for the effect modification by $\mathrm{O}_{3}$ are displayed in Figure 4 . We found increasing effects of temperature for increasing levels of ozone in the north, with a $+6.5 \%$ change in mortality $\left(95 \%\right.$ CI: $\left.-0.3-13.8 \mathrm{I}^{2}=64 \%\right)$ for low, $+10.1 \%\left(95 \%\right.$ CI: $\left.4.8-15.8 \mathrm{I}^{2}=65 \%\right)$ for medium, and $+14.8 \%$ (95\% CI: 9.7-20.2 $\mathrm{I}^{2}=39 \%$ ) for high levels of $\mathrm{O}_{3}$. The results for central cities showed a similar pattern, with temperature estimates for increasing $\mathrm{O}_{3}$ concentrations equal to $+7.1 \%(95 \% \mathrm{CI}$ : $\left.-1.1-16.1 \mathrm{I}^{2}=0 \%\right),+15.5 \%$ (95\% CI: $\left.10.2-21.0 \mathrm{I}^{2}=0 \%\right)$, and $+24.1 \%\left(95 \%\right.$ CI: $\left.15.6-33.3 \mathrm{I}^{2}=32 \%\right)$, respectively. In contrast, no effect modification was observed in southern cities, the increase in temperature-related mortality being constant among the three levels of air pollution $(+12.6 \%$; $95 \% \mathrm{CI}$ : $2.8-23.4 \mathrm{I}^{2}=55 \%,+13.6 \%$; $95 \%$ CI: $6.3-21.5 \mathrm{I}^{2}=67 \%,+13.4 \%$; $95 \%$ CI: $4.1-23.5 \mathrm{I}^{2}=60 \%$ from low to high $\mathrm{O}_{3}$ values). The overall pooled analysis showed a positive interaction but was more contained compared to the one estimated for PM10. 


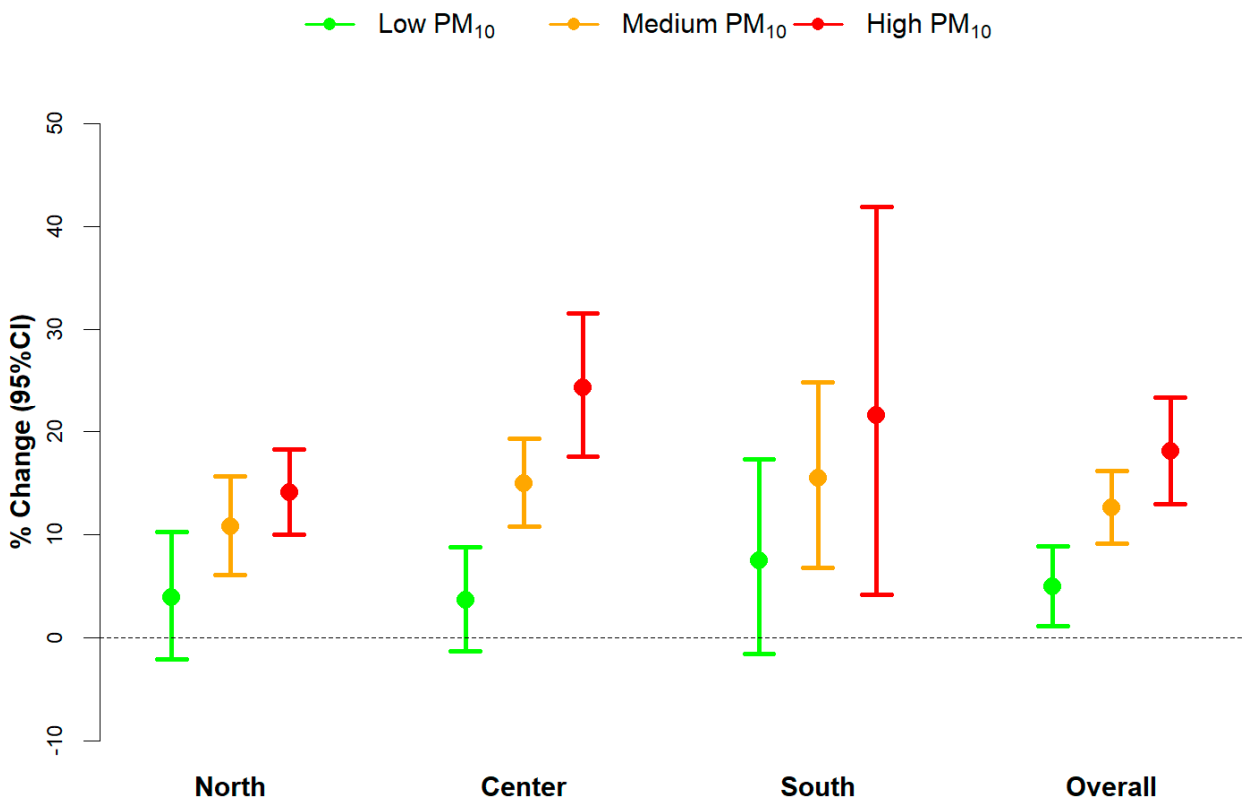

Figure 3. Area-specific (North, Center, South) and overall meta-analytical estimates of the heat effects, stratified by levels of PM10. Estimates are given as \% change in non-accidental mortality, and 95\% confidence intervals ( $95 \% \mathrm{CI}$ ) for mean air temperature increases between the 75th to 99th percentile of city-specific temperature distributions, by levels of PM10 (defined as "low", "medium", and "high" based on 5th, 50th, and 95th percentiles of city-specific PM10 distributions).

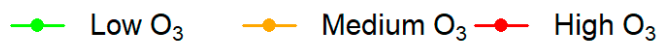

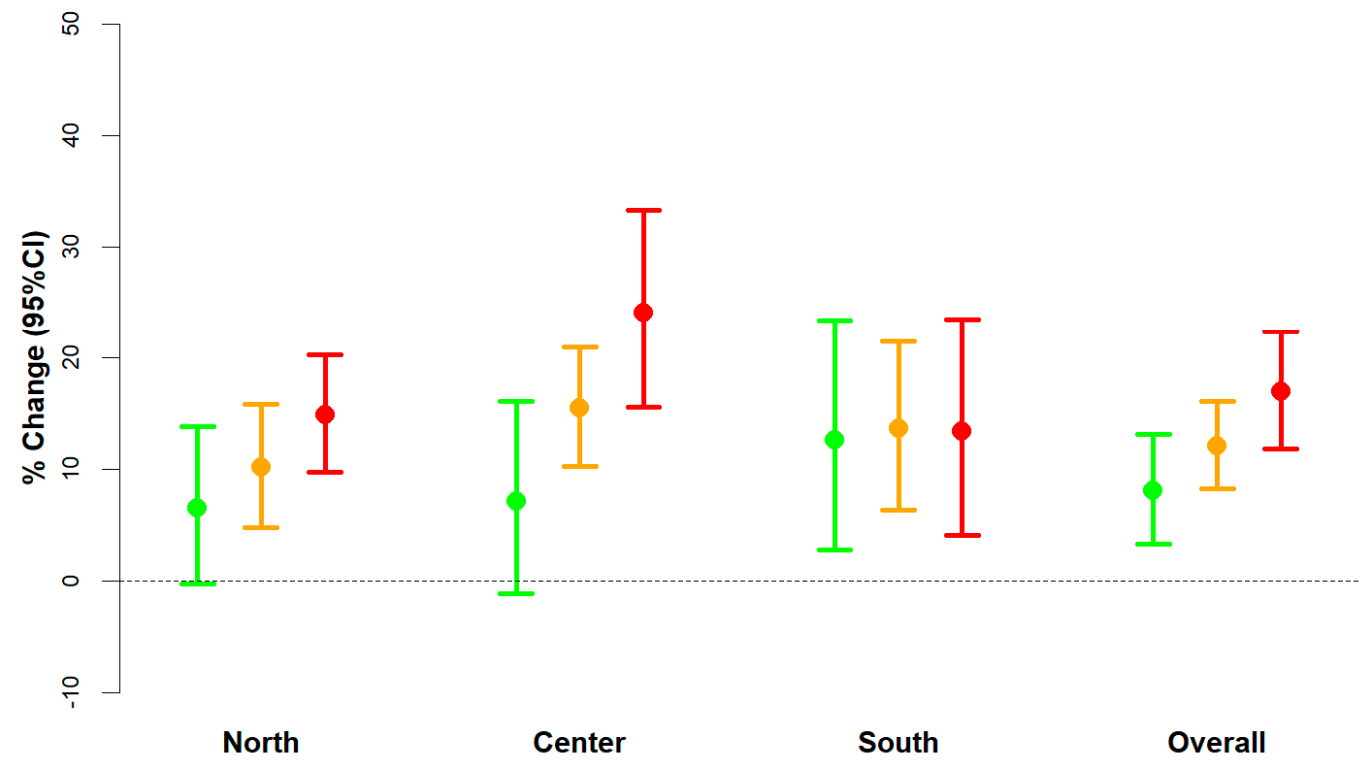

Figure 4. Area-specific (North, Center, South) and overall meta-analytical estimates of the heat effects, stratified by levels of $\mathrm{O}_{3}$. Estimates are given as \% change in non-accidental mortality, and $95 \%$ confidence intervals ( $95 \% \mathrm{CI}$ ) for mean air temperature increases between the 75th to 99th percentile of city-specific temperature distributions, by levels of $\mathrm{O}_{3}$ (defined as "low", "medium", and "high" based on 5th, 50th, and 95th percentiles of city-specific $\mathrm{O}_{3}$ distributions). 


\section{Discussion}

The present study investigated the joint relationship between summer temperatures and air pollutants on daily mortality in 25 Italian cities using innovative approaches for estimating non-linear associations and effect modification. We confirmed a high and significant effect of high summer temperatures on daily mortality. City-specific tensor smoothers showed increased risks per increasing levels of both exposures, suggesting a synergistic effect on mortality, i.e., a joint effect greater than the sum of individual effects. Finally, we detected an effect modification induced by both air pollutants (PM10 and $\mathrm{O}_{3}$ ) on the temperature-mortality association, with highest temperature-related mortality on days with high air pollution concentrations.

Our results can be compared with the existing evidence from the epidemiological literature, which analysed a synergy between extreme temperatures and high concentrations of air pollution in increasing daily mortality risks $[18-20,22,28,29]$. The evidence on effect modification induced by air pollution from previous studies is limited and with mixed results. Evidence for modification by particles and ozone was provided by a multicenter European study considering heat waves instead of temperature effects [20], while a large nine cities US study did not find any evidence of interaction between temperature and outdoor PM2.5 or ozone [30]. A study on Lisbon and Berlin found a different pattern of effect modification in the two cities by PM10 since the pollutant increased in summer in the first city and decreased in the second one [19], while both cities recorded a synergistic effect between high temperature and ozone.

The research question of the effect modification induced by air pollution in the temperature-mortality relationship is worth considering the heat related effects are large compared to air pollution, therefore the study of the potential modification has a greater public health relevance especially since heat response plans are in place in many cities but virtually none includes information on air pollution [31]. Air pollutants may have synergistic effects with high temperature in different ways, by increasing exposure levels in the atmosphere, by enhancing the intake of pollutants within the human body and through interconnected pathogenetic pathways. The first level of interaction is depicted by the air pollution peaks occurring during stagnation events common in summer heat waves $[32,33]$ and by the photochemical reactions producing ozone in the atmosphere under conditions often related to heat waves (high solar irradiance and high temperature). Moreover, it has been suggested that during the warmer months, when people spend more time outdoors or keep windows open, exposure to atmospheric pollutants and heat are greater with potential detrimental effects on health, especially among the most vulnerable subgroups [15]. The second type of interactions is due to the activation of thermoregulatory mechanisms such as the increase in ventilation rate that consequently increase the intake of air pollutants into the airways [34]. The third level of interaction is within the body especially in vulnerable subjects but mechanisms are little known. A possible explanation is that thermoregulatory responses to heat stress conditions may reduce the ability of the body to detoxify chemicals [34], but specific pathways are possibly triggered by ozone and by particles interactive effects. Ozone has a potent oxidant toxicity for the lung and impairs host defenses against respiratory infections, further aggravating the heat-related effects on the body [35]. Particulate matter seems to activate the same cellular pathways than high temperature, e.g., growing levels of markers of systemic inflammation such as C-reactive protein, by potentiating temperature effects [36,37].

Our study has a national representativeness and allows to evaluate geographical heterogeneity of temperature-air pollution interactions. The largest interactions were in the central and northern cities. Such geographical differences do not rely on air pollution effects heterogeneity [1], but they could be explained by local climatic conditions affecting population capacity to cope with different summer temperature ranges and by differences in population susceptibility (e.g., $\% 65+$ years old population has an inverse North-South gradient in Italy ranging from $18 \%$ in the South to $25 \%$ in the North).

This is one of the few studies which hypothesized a possible effect modification induced by air pollutants in the temperature-mortality relationship and found evidence of a higher temperature-related mortality risk on very polluted days. This result has important consequences, 
as the frequency of extreme meteorological conditions will increase over time, and there is evidence of stable air pollution effects documented even at low concentrations. This has been predicted in the Mediterranean hot spot [32,33]. Our study confirms a North-South gradient in heat effects; southern areas are highly exposed to heat stressful conditions in summer and scenarios for the Mediterranean basin show a disproportionate increase in heat wave duration and intensity compared to the other European regions [23]. Furthermore an increase in stagnation episodes in the same area is expected, favoring photochemical reactions and increasing persistence of pollutants [38]. Both environmental exposures especially affect the most vulnerable subgroups, such as the elderly and those with pre-existing cardio-respiratory conditions [6,7]. Furthermore, it is known that the elderly population has been increasing over the last decades [39], and it represents a pool of susceptible individuals upon which prevention measures should be targeted to, in order to minimize the joint impact of extreme temperatures and air pollution.

This paper highlights the relevance of the acute effects of heat and air pollution, that should be accounted for when calculating the whole health burden, in addition to the long-term effects which are very serious for air pollution, classified as carcinogenic to humans (Group 1) by the International Agency for Research on Cancer [38].

Strengths of the study include the fact it assesses whether daily air pollution might modify the short-term association between summer temperature and mortality in 25 cities, representative of diverse geographical and climatic conditions. Secondly, the use of tridimensional non-parametric curves allowed us to relax linearity assumptions often underlying time-series studies, while providing more flexible and robust estimates. Among the weaknesses of the study, it is important to highlight the ecological study design, which assumes the exposure is the same over the entire spatial domain (city) which is a limit in all time-series studies. The study only accounts for urban areas as both temperature and air quality monitors are lacking in sub-urban and rural settings in Italy. Another limitation is that only mortality for all natural causes was used; this choice was made since we modeled the interaction with a bivariate tensor smoother, requiring a considerable number of daily outcome counts in order to converge.

\section{Conclusions}

The present study underlines the importance of jointly investigating the short-term health effects of air pollution and air temperature in order to fully capture the health effects during summer. In Italy, high and significant effects of heat on daily mortality in summer are shown. Furthermore, although there are some geographical differences, the risk in heat-related mortality is greatest when high levels of PM10 and ozone occur. Since future vulnerability to both heat waves and air pollutants is expected to become a major concern in the Mediterranean countries such as Italy [23,24,32,33], in light of the synergies between the two exposures, heat adaptation and response plans should incorporate such interactions into warning systems and prevention measures especially among vulnerable subgroups.

Supplementary Materials: The following are available online at http:/ /www.mdpi.com/1660-4601/15/8/1771/s1. Table S1: City-specific all ages resident population by age groups (average 2001-2010). Table S2: City-specific (North, Center, South) estimates of the heat effect, stratified by levels of PM10. Estimates are expressed as \% change in non-accidental mortality, and 95\% confidence intervals (95\% CI) per increases of mean air temperatures from 75th to 99th percentile of city-specific temperature distributions, by levels of PM10 (defined as "low," "medium," and "high" based on 5th, 50th, and 95th percentiles of city-specific PM10 distributions). Table S3: City-specific (North, Center, South) estimates of the heat effect, stratified by levels of ozone $\left(\mathrm{O}_{3}\right)$. Estimates are expressed as $\%$ change in non-accidental mortality, and $95 \%$ confidence intervals $(95 \% \mathrm{CI})$ per increases of mean air temperatures from 75th to 99th percentile of city-specific temperature distributions, by levels of $\mathrm{O}_{3}$ (defined as "low," "medium," and "high" based on 5th, 50th, and 95th percentiles of city-specific $\mathrm{O}_{3}$ distributions).

Author Contributions: Conceptualization, M.S., M.S., F.K.d.D., and P.M.; Methodology, M.S. and M.S.; Formal Analysis, M.S.; Writing-Original Draft Preparation, M.S., M.S., and F.K.d.D.; Writing—Review \& Editing, F.K.d.D. and M.D.S.; Supervision, P.M. and M.D.

Funding: The study was partially supported "The Italian National Heat Prevention Plan" of the Italian Ministry of Health, Centers for Disease Control and Prevention CUP J85I16000260001. 
Acknowledgments: Authors acknowledge "The Italian National Heat Prevention Plan" of the Italian Ministry of Health, Centers for Disease Control and Prevention, and the Italian EPIAR Collaborative Group.

Conflicts of Interest: The authors declare no conflict of interest.

\section{References}

1. Alessandrini, E.R.; Faustini, A.; Chiusolo, M.; Stafoggia, M.; Gandini, M.; Demaria, M.; Antonelli, A.; Arena, P.; Biggeri, A.; Canova, C.; et al. Air pollution and mortality in twenty-five Italian cities: Results of the EpiAir2 Project. Epidemiol. Prev. 2013, 37, 220-229. [PubMed]

2. Achilleos, S.; Kioumourtzoglou, M.-A.; Wu, C.-D.; Schwartz, J.D.; Koutrakis, P.; Papatheodorou, S.I. Acute effects of fine particulate matter constituents on mortality: A systematic review and meta-regression analysis. Environ. Int. 2017, 109, 89-100. [CrossRef] [PubMed]

3. De' Donato, F.K.; Leone, M.; Scortichini, M.; De Sario, M.; Katsouyanni, K.; Lanki, T.; Basagaña, X.; Ballester, F.; Åström, C.; Paldy, A.; et al. Changes in the effect of heat on mortality in the last 20 years in nine European cities. Results from the PHASE project. Int. J. Environ. Res. Public Health 2015, 12, 15567-15583. [CrossRef] [PubMed]

4. $\quad$ Bunker, A.; Wildenhain, J.; Vandenbergh, A.; Henschke, N.; Rocklov, J.; Hajat, S.; Sauerborn, R. Effects of Air Temperature on Climate-Sensitive Mortality and Morbidity Outcomes in the Elderly; a Systematic Review and Meta-analysis of Epidemiological Evidence. EBioMedicine 2016, 6, 258-268. [CrossRef] [PubMed]

5. Guo, Y.; Gasparrini, A.; Armstrong, B.; Li, S.; Tawatsupa, B.; Tobias, A.; Lavigne, E.; Coelho, M.D.S.Z.S.; Leone, M.; Pan, X.; et al. Global variation in the effects of ambient temperature on mortality: A systematic evaluation. Epidemiology 2014, 25, 781. [CrossRef] [PubMed]

6. Benmarhnia, T.; Deguen, S.; Kaufman, J.S.; Smargiassi, A. Vulnerability to heat-related mortality: A systematic review, meta-analysis, and meta-regression analysis. Epidemiology 2015, 26, 781-793. [CrossRef] [PubMed]

7. Bell, M.L.; Zanobetti, A.; Dominici, F. Evidence on Vulnerability and Susceptibility to Health Risks Associated With Short-Term Exposure to Particulate Matter: A Systematic Review and Meta-Analysis. Am. J. Epidemiol. 2013, 178, 865-876. [CrossRef] [PubMed]

8. Morelli, X.; Rieux, C.; Cyrys, J.; Forsberg, B.; Slama, R. Air pollution, health and social deprivation: A fine-scale risk assessment. Environ. Res. 2016, 147, 59-70. [CrossRef] [PubMed]

9. Carugno, M.; Consonni, D.; Randi, G.; Catelan, D.; Grisotto, L.; Alberto, P.; Biggeri, A.; Baccini, M. Air pollution exposure, cause-specific deaths and hospitalizations in a highly polluted Italian region. Environ. Res. 2016, 147, 415-424. [CrossRef] [PubMed]

10. Stafoggia, M.; Forastiere, F.; Agostini, D.; Biggeri, A.; Bisanti, L.; Cadum, E.; Caranci, N.; De'Donato, F.; De Lisio, S.; De Maria, M.; et al. Vulnerability to heat-related mortality: A multicity, population-based, case-crossover analysis. Epidemiology 2006, 17, 315-323. [CrossRef] [PubMed]

11. Stafoggia, M.; Forastiere, F.; Faustini, A.; Biggeri, A.; Bisanti, L.; Cadum, E.; Cernigliaro, A.; Mallone, S.; Pandolfi, P.; Serinelli, M.; et al. Susceptibility factors to ozone-related mortality: A population-based case-crossover analysis. Am. J. Respir. Crit. Care Med. 2010, 182, 376-384. [CrossRef] [PubMed]

12. Turner, L.R.; Barnett, A.G.; Connell, D.; Tong, S. Ambient Temperature and Cardiorespiratory Morbidity. Epidemiology 2012, 23, 594-606. [CrossRef] [PubMed]

13. Jhun, I.; Fann, N.; Zanobetti, A.; Hubbell, B. Effect modification of ozone-related mortality risks by temperature in 97 US cities. Environ. Int. 2014, 73, 128-134. [CrossRef] [PubMed]

14. Qian, Z.; Lin, H.-M.; Stewart, W.F.; Kong, L.; Xu, F.; Zhou, D.; Zhu, Z.; Liang, S.; Chen, W.; Shah, N.; et al. Seasonal Pattern of the Acute Mortality Effects of Air Pollution. J. Air Waste Manag. Assoc. 2010, 60, 481-488. [CrossRef] [PubMed]

15. Stafoggia, M.; Schwartz, J.; Forastiere, F.; Perucci, C.A. Does Temperature Modify the Association between Air Pollution and Mortality? A Multicity Case-Crossover Analysis in Italy. Am. J. Epidemiol. 2008, 167, 1476-1485. [CrossRef] [PubMed]

16. Li, J.; Woodward, A.; Hou, X.-Y.; Zhu, T.; Zhang, J.; Brown, H.; Yang, J.; Qin, R.; Gao, J.; Gu, S.; et al. Modification of the effects of air pollutants on mortality by temperature: A systematic review and meta-analysis. Sci. Total Environ. 2017, 575, 1556-1570. [CrossRef] [PubMed]

17. Chen, F.; Fan, Z.; Qiao, Z.; Cui, Y.; Zhang, M.; Zhao, X.; Li, X. Does temperature modify the effect of PM10 on mortality? A systematic review and meta-analysis. Environ. Pollut. 2017, 224, 326-335. [CrossRef] [PubMed] 
18. Breitner, S.; Wolf, K.; Devlin, R.B.; Diaz-Sanchez, D.; Peters, A.; Schneider, A. Short-term effects of air temperature on mortality and effect modification by air pollution in three cities of Bavaria, Germany: A time-series analysis. Sci. Total Environ. 2014, 485, 49-61. [CrossRef] [PubMed]

19. Burkart, K.; Canário, P.; Breitner, S.; Schneider, A.; Scherber, K.; Andrade, H.; Alcoforado, M.J.; Endlicher, W. Interactive short-term effects of equivalent temperature and air pollution on human mortality in Berlin and Lisbon. Environ. Pollut. 2013, 183, 54-63. [CrossRef] [PubMed]

20. Analitis, A.; Michelozzi, P.; D'Ippoliti, D.; De'donato, F.; Menne, B.; Matthies, F.; Atkinson, R.W.; Iñiguez, C.; Basagaña, X.; Schneider, A.; et al. Effects of heat waves on mortality: Effect modification and confounding by air pollutants. Epidemiology 2014, 25, 15-22. [CrossRef] [PubMed]

21. McCormack, M.C.; Belli, A.J.; Waugh, D.; Matsui, E.C.; Peng, R.D.; Williams, D.L.; Paulin, L.; Saha, A.; Aloe, C.M.; Diette, G.B.; et al. Respiratory Effects of Indoor Heat and the Interaction with Air Pollution in Chronic Obstructive Pulmonary Disease. Ann. Am. Thorac. Soc. 2016, 13, 2125-2131. [CrossRef] [PubMed]

22. Li, G.; Jiang, L.; Zhang, Y.; Cai, Y.; Pan, X.; Zhou, M. The impact of ambient particle pollution during extreme-temperature days in Guangzhou City, China. Asia-Pac. J. Public Health 2014, 26, 614-621. [CrossRef] [PubMed]

23. Kovats, R.S.; Valentini, R.; Bouwer, L.M.; Georgopoulou, E.; Jacob, D.; Martin, E.; Rounsevell, M.; Soussana, J.-F. Europe. In Climate Change 2014: Impacts, Adaptation, and Vulnerability Part B: Regional Aspects. Contribution of Working Group II to the Fifth Assessment Report of the Intergovernmental Panel on Climate Change; Barros, V.R., Field, C.B., Dokken, D.J., Mastrandrea, M.D., Mach, K.J., Bilir, T.E., Chatterjee, M., Ebi, K.L., Estrada, Y.O., Genova, R.C., et al., Eds.; Cambridge University Press: Cambridge, UK; New York, NY, USA, 2014; pp. 1267-1326.

24. ISPRA. Annual Report on the State of the Environment, 15th ed.; National Institute of Environmental Protection and Research: Rome, Italy, 2017; ISBN 978-88-448-0863-1.

25. Gandini, M.; Berti, G.; Cattani, G.; Faustini, A.; Scarinzi, C.; De’Donato, F.; Accetta, G.; Angiuli, L.; Caldara, S.; Carreras, G.; et al. Environmental indicators in EpiAir2 project: Air quality data for epidemiological surveillance. Epidemiol. Prev. 2013, 37, 209-219. [PubMed]

26. Baccini, M.; Biggeri, A.; Accetta, G.; Kosatsky, T.; Katsouyanni, K.; Analitis, A.; Anderson, H.R.; Bisanti, L.; D’Iippoliti, D.; Danova, J.; et al. Heat Effects on Mortality in 15 European Cities. Epidemiology 2008, 19, 711-719. [CrossRef] [PubMed]

27. R Development Core Team. R: A Language and Environment for Statistical Computing, version 2.0-0; The R Foundation for Statistical Computing: Vienna, Austria, 2011.

28. Ren, C.; Williams, G.M.; Tong, S. Does particulate matter modify the association between temperature and cardiorespiratory diseases? Environ. Health Perspect. 2006, 114, 1690-1696. [CrossRef] [PubMed]

29. Ren, C.; Williams, G.M.; Morawska, L.; Mengersen, K.; Tong, S. Ozone modifies associations between temperature and cardiovascular mortality: Analysis of the NMMAPS data. Occup. Environ. Med. 2008, 65, 255-260. [CrossRef] [PubMed]

30. Zanobetti, A.; Schwartz, J. Temperature and mortality in nine US cities. Epidemiology 2008, 19, 563-570. [CrossRef] [PubMed]

31. Bittner, M.-I.; Matthies, E.F.; Dalbokova, D.; Menne, B. Are European countries prepared for the next big heat-wave? Eur. J. Public Health 2014, 24, 615-619. [CrossRef] [PubMed]

32. Horton, D.E.; Skinner, C.B.; Singh, D.; Diffenbaugh, N.S. Occurrence and persistence of future atmospheric stagnation events. Nat. Clim. Chang. 2014, 4, 698-703. [CrossRef] [PubMed]

33. Doherty, R.M.; Heal, M.R.; O'Connor, F.M. Climate change impacts on human health over Europe through its effect on air quality. Environ. Health 2017, 16, 118. [CrossRef] [PubMed]

34. Gordon, C.J. Role of environmental stress in the physiological response to chemical toxicants. Environ. Res. 2003, 92, 1-7. [CrossRef]

35. Schelegle, E.S.; Morales, C.A.; Walby, W.F.; Marion, S.; Allen, R.P. 6.6-hour inhalation of ozone concentrations from 60 to 87 parts per billion in healthy humans. Am. J. Respir. Crit. Care Med. 2009, 180, 265-272. [CrossRef] [PubMed]

36. Wilker, E.H.; Yeh, G.; Wellenius, G.A.; Davis, R.B.; Phillips, R.S.; Mittleman, M.A. Ambient temperature and biomarkers of heart failure: A repeated measures analysis. Environ. Health Perspect. 2012, 120, 1083-1087. [CrossRef] [PubMed] 
37. Li, W.; Dorans, K.S.; Wilker, E.H.; Rice, M.B.; Ljungman, P.L.; Schwartz, J.D.; Coull, B.A.; Koutrakis, P.; Gold, D.R.; Keaney, J.F., Jr.; et al. Short-Term Exposure to Ambient Air Pollution and Biomarkers of Systemic Inflammation: The Framingham Heart Study. Arterrioscler. Thromb. Vasc. Biol. 2017, 37, 1793-1800. [CrossRef] [PubMed]

38. IARC Working Group on the Evaluation of Carcinogenic Risks to Humans. Outdoor Air Pollution. IARC Monogr Eval Carcinog Risks Hum. 2016, 109, 9-444.

39. Michelozzi, P.; De' Donato, F.; Scortichini, M.; De Sario, M.; Asta, F.; Agabiti, N.; Guerra, R.; de Martino, A.; Davoli, M. On the increase in mortality in Italy in 2015: Analysis of seasonal mortality in the 32 municipalities included in the Surveillance system of daily mortality. Epidemiol. Prev. 2016, 40, 22-28. [CrossRef] [PubMed]

2018 by the authors. Licensee MDPI, Basel, Switzerland. This article is an open access article distributed under the terms and conditions of the Creative Commons Attribution (CC BY) license (http://creativecommons.org/licenses/by/4.0/). 